\title{
REVIEW
}

\section{Digital imaging techniques in otolith data capture, analysis and interpretation}

\author{
Mark Fisher ${ }^{1, *}$, Ewan Hunter ${ }^{2,3}$ \\ ${ }^{1}$ School of Computing Sciences, University of East Anglia, Norwich Research Park, Norwich NR4 7TJ, UK \\ ${ }^{2}$ Centre for the Environment, Fisheries and Aquaculture Sciences (CEFAS), Lowestoft, Suffolk NR33 0HT, UK \\ ${ }^{3}$ School of Environmental Sciences, University of East Anglia, Norwich Research Park, Norwich NR4 7TJ, UK
}

\begin{abstract}
Otoliths or ear-stones are hard, calcium carbonate structures located within the inner ear of bony fishes. Counts of rings and measurements of seasonal growth increments from otoliths are important metrics for assessment and management of fish stocks, and the preparation and microscopic analysis of otoliths forms an essential part of the routine work undertaken by fisheries scientists worldwide. Otolith analysis is a skilled task requiring accuracy and precision, but it is laborious, time-consuming to perform, and represents a significant cost to fisheries management. In the last 2 decades, several attempts to apply 'computer vision' (systems that perform high-level tasks and exhibit intelligent behaviour) in otolith analysis have been reported. Although considerable progress has been made and several prototype systems developed, laboratories have been reluctant to adopt image-based computer-assisted age and growth estimation (CAAGE) systems. This paper surveys applications of CAAGE, focusing on their utility for automated ageing using images of otolith macrostructure. A cost-benefit analysis of CAAGE of cod, plaice and anchovy shows that computer vision performs relatively poorly compared with morphometric techniques. However, there is evidence that information from visual features can boost the performance of morphometric CAAGE, and further work is needed to develop effective frameworks for this integrated approach. The cost benefit of these systems might be attractive to smaller laboratories that are already using age-length keys derived from otolith morphometrics for management of smaller artisanal fisheries.
\end{abstract}

KEY WORDS: Otolith · Computer-assisted age and growth estimation · CAAGE - Image analysis · Computational model

\section{INTRODUCTION}

The population models used in fisheries management require age data to define stock characteristics (Cadima 2003, Cadrin \& Dickey-Collas 2015). For most commercially exploited fish stocks, this information is determined from an analysis of seasonally accreted growth marks in the calcified structures (scales, bones, fin rays, otoliths) of fish (Welch et al. 1993, Panfili et al. 2002, Brophy 2014, Zhu et al. 2015). The calcified inner ear-stones of bony fishes,

\footnotetext{
${ }^{*}$ Corresponding author: mark.fisher@uea.ac.uk
}

or otoliths, have been a cornerstone of fish ageing methodology for over a century, as otolith rings are formed with regular periodicity (Williams \& Bedford 1974, Mendoza 2006). The literature on ageing of fish stocks continues to grow; however, the approach is essentially subjective. While expert otolith readers can enumerate the annual increments for many stocks with a good degree of accuracy and high precision, ageing certain stocks and older individuals can be very challenging (Campana 2001, Morison et al. 2005, de Pontual et al. 2006, Fey \& Linkowski

(C) M. Fisher and The Crown 2018. Open Access under Creative Commons by Attribution Licence. Use, distribution and reproduction are unrestricted. Authors and original publication must be credited. 
2006, Smith 2014, Hüssy et al. 2016a). Otoliths act as endolymphatic infillings (masses) within the saccule of the inner ear and function as auditory, balance, movement, and direction receptors in all vertebrates and some aquatic invertebrates (Popper \& Hoxter 1981, Popper et al. 2005, Schulz-Mirbach et al. 2015). Bony fish (teleosts) possess 3 pairs of otoliths (sagittae, lapilli and asterisci), and in most species, the saccular sagitta is the largest otolith and the focus of most scientific inquiries (Fig. 1). Otoliths grow according to an accretionary process of calcium carbonate deposition that builds as a succession of concentric layers from an inner core. Inter-specific variability in the shapes and proportional sizes of otoliths is substantial, and often diagnostic (Schmidt 1969, Messieh 1972, Campana \& Casselman 1993, Friedland \& Reddin 1994, Lombarte \& Morales-Nin 1995). Considerable research effort has been expended examining the biomineralisation process that drives otolith growth and factors affecting the seasonal formation of annuli and other growth marks, but our understanding is currently incomplete and the mechanics of the otolith structure and composition continues to be an active topic of research (Jolivet et al. 2008,
2013, Morales-Nin \& Geffen 2015). The individual biochronologies encoded as growth marks are thought to reflect environmental experience, since the composite calcium carbonate is primarily derived from the ambient water, but recent research suggests that physiological factors also play an important role (Darnaude et al. 2014, Sturrock et al. 2015, Hüssy et al. 2016a, Smolinski \& Mirny 2017). Typically, there is more growth in summer, less in winter, and this annual cycle manifests as a macrostructure (MaS) exhibiting translucent rings, somewhat similar to tree rings. In many species, the accretion of calcium carbonate and glutinous matrix alternates on a daily cycle, and this periodicity is particularly evident in microscope examinations of otolith microstructure (MiS) in juvenile fish (Campana \& Neilson 1985). As otolith shape is indicative of fish species and related to life history and behaviour (Popper \& Lu 2000), this structure has attracted the interest of fisheries scientists since at least 1899 (Ricker 1975).

Consequently, data gathered from otoliths has been applied in fisheries science worldwide for over a century, with otoliths forming the basis of routine assessment of age and structure of fish stocks. Cam-

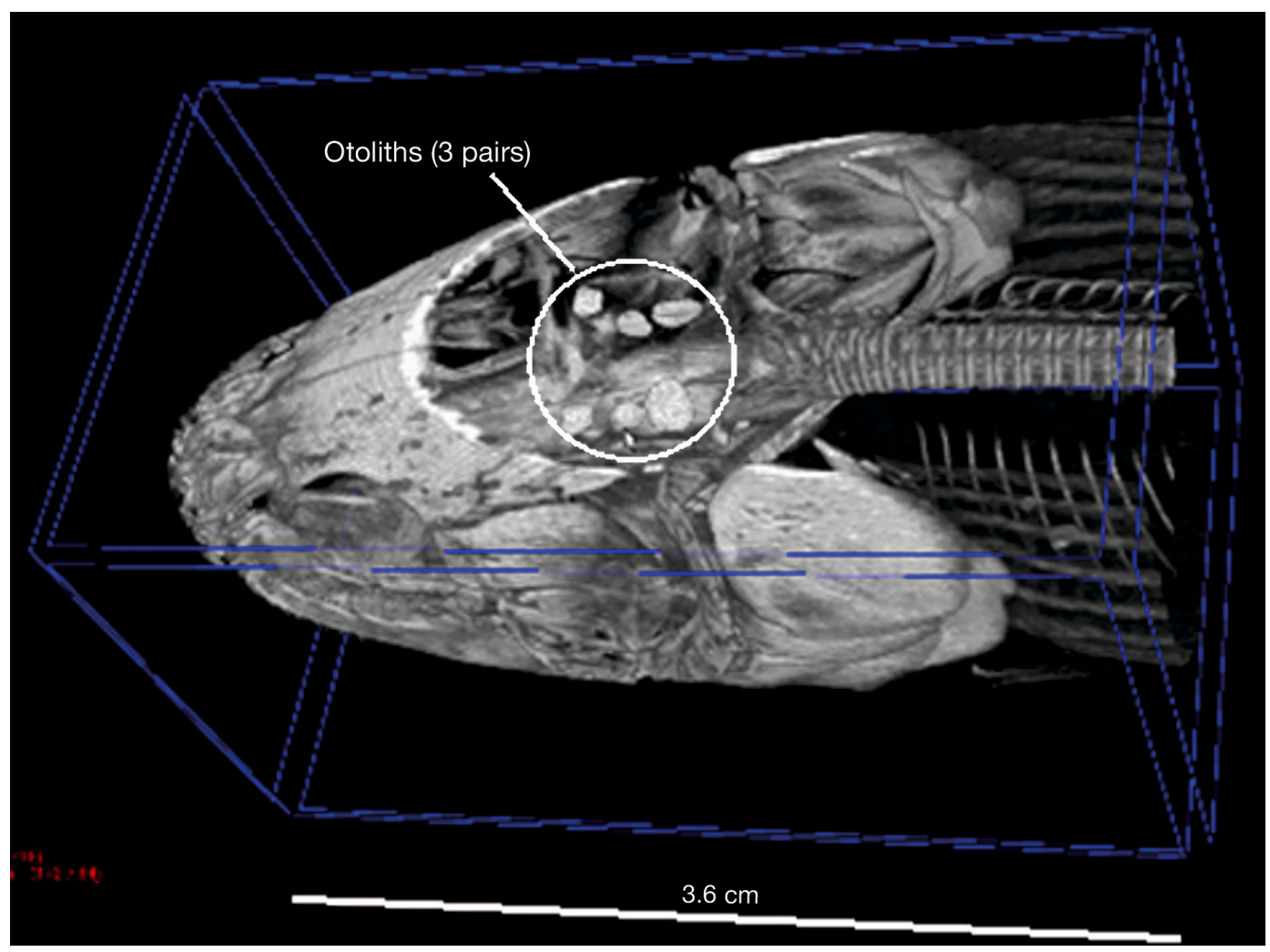

Fig. 1. Micro-computed tomography (micro-CT) image of bowfin Amia calva showing the in situ location of otoliths (sagittae, lapilli and asterisci), representative of all bony fish (teleosts). Data comprises 1071 slices $(1024 \times 1024$ pixels $)$ along the coronal axis; each slice is $0.1237 \mathrm{~mm}$ thick, with an interslice spacing of $0.1237 \mathrm{~mm}$ 
pana \& Thorrold (2001) estimated the minimum number of otoliths examined worldwide to be between 800000 and 2000000 per annum, underlining their importance in monitoring and characterising fish populations. Fish have indeterminate growth patterns that are influenced by environmental conditions, and as such, fish growth and production require frequent measurement to monitor productivity and population characteristics in response to varying levels of exploitation and environmental change. Campana (2001) discusses the importance of this work and highlights several examples where inaccuracies in age determination have led to age estimates that differ by up to a factor of 3 , leading in turn to overly optimistic estimates of growth and mortality in certain species that have contributed to overexploitation (e.g. de Pontual et al. 2006). In addition to annual ageing and otolith MiS, more recent reviews (Begg et al. 2005, Campana 2005) highlight emerging applications such as otolith chemistry, and the literature continues to grow (Geffen 2012, Sturrock et al. 2012), underlining the ongoing relevance of otoliths to innovations in fisheries science.

The feasibility of using digital imaging in fish ageing studies has been investigated since Fawel (1974) first reported results using a video camera and digital frame store. Further use of computerassisted ageing techniques followed (Methot 1981, Frei 1982, Messieh \& McDougall 1985, Campana 1987, McGowen et al. 1987, Panfili et al. 1990) with the availability of cheaper personal computers. Protocols and potential advantages of computerassisted analysis of MiS and MaS were investigated by Campana (1992) and King (1993). Routine tasks which have attracted the attention of the imageprocessing community are fish age determination and the measurement of inter-annual growth increments (Troadec 1991, Morales-Nin et al. 1998, Takashima et al. 2000, Campana \& Thorrold 2001, Troadec \& Benzinou 2002, Begg et al. 2005, Black et al. 2005). Other areas where image analysis has played an important role are otolith allometry and morphometrics for distinguishing between fish stocks (Cardinale et al. 2004, Burke et al. 2008a,b, Parisi-Baradad et al. 2010), quality assurance (Morison et al. 1998, 2005, Palmer et al. 2005) and environmental reconstruction (Millner et al. 2011, Morrongiello et al. 2012).

Routine capture and analysis of otolith images has formed an important component of European Union (EU)-funded collaborative fisheries research since 1996, with projects focused on improving the accuracy of otolith ageing (Moksness 2000, Appelberg et al. 2005), age determination by otolith shape (Arneri et al. 2002) and automatic age determination and growth analysis (Mahé 2009, Mahé et al. 2017). Digital imaging offers a number of potential advantages, including the development of online scientific archives and historical records (Lombarte et al. 2006), the rapid calculation of biological and life history information (Carbini et al. 2008), and the automated capture and seamless storage of associated information (Morison et al. 1998). Some EU projects have delivered specialised algorithms and spawned bespoke software environments for otolith imaging, such as IMAGIC (Image Science Software) and TNPC (Mahé 2009, Mahé et al. 2011). Two hundred copies of TPNC are licenced and it is cited in research (e.g. de Pontual et al. 2006, Mille et al. 2016) and used in routine survey analysis. However, much of the literature on computer-assisted sclerochronology is dominated by generic proprietary microscopy tools such as ImagePro (Media Cybernetics ${ }^{\circledR}$ ), Lucia (Laboratory Imaging ${ }^{\circledR}$ ) and opensource systems such as ImageJ (formerly NIH image) (Abràmoff et al. 2004). Examples include Whitman \& Johnson's (2016) tutorial featuring ImagePro and an ImageJ plug-in for otolith and tree ring counting resulted from research sponsored by the Norwegian Institute of Marine Research, but there is no evidence that this has been evaluated (Vischer \& Nastase 2015).

Panfili et al. (1990) originally coined the phrase 'computer-assisted age and growth estimation' (CAAGE) to describe interactive imaging tools, and this name is still used to describe more recent systems that operate completely autonomously. Such systems are attractive in that they seem to offer the possibility of moving from subjective estimates of age towards objective measures. However, these systems have been very difficult to implement. In an observation that remains true to this day, Morison et al. (2005) observed,

'it is a recognition of the complexity of the process that no age estimation laboratories have been able to replace their human readers' (Morison et al. 2005, p. 777).

This review aims to provide an overview of imaging and pattern recognition systems for routine automated ageing through computerised analysis of growth marks that present in the otolith MaS. The work builds on a previous tutorial introduction by Troadec \& Benzinou (2002) and conference presentation by Carbini et al. (2008). We highlight results of the most comprehensive evaluation of CAAGE techniques and methodology undertaken by an EUfunded project entitled Automated FISh Ageing 
(AFISA) (Mahé 2009). In reviewing this work and attempts by others to develop automatic imagebased ageing tools, we try to explain why there has been relatively little activity in this area since a flurry of articles were published in the 2000s. We highlight an existing approach to integrating information from otolith images within existing morphometric CAAGE systems which we believe could be further developed and exploited more widely. We also signpost future frameworks that could be developed to enable experts and computers to work cooperatively, and we believe that these systems may have a role in training and quality assurance.

\section{REVIEW OF TECHNIQUES}

Image processing has been used in sclerochronology since the 1980s and initially focused on low-level image-processing tasks aimed at facilitating interactive systems to assist scientists in making measurements and recording results (Campana 1987, McGowen et al. 1987, Small \& Hirschhorn 1987, Panfili et al. 1990). In the 1990s, scientists considered highlevel tasks such as classification of otolith shape (for discrimination between stocks), and CAAGE systems were designed to analyse 1-dimensional (1-D) opacity signals recovered from a ray (transect) originating at the nucleus and extending to the otolith edge (Troadec 1991, Macy 1995, Welleman \& Storbeck 1995, Cailliet et al. 1996) (Table 1). Later, CAAGE advanced to take advantage of 2-dimensional (2-D) algorithms and growth models. We consider these in the section 'Image processing', after first reviewing the important step of image acquisition.

\section{Image acquisition}

Age-related studies of otoliths can be broadly divided into those involving $\mathrm{MaS}$, such as routine age determination from annual rings or species identification (Morales-Nin \& Panfili 2002, Courbin et al. 2007), or those involving MiS, for example nucleus or daily incremental width and primordia studies (Campana \& Neilson 1985, Geffen 2002, Neat et al. 2008). Although all researchers agree that the method used for otolith preparation and examination with microscopy is key in obtaining high-quality images, the imaging techniques employed vary depending on established protocols within each laboratory. A survey by Morison et al. (2005) concludes that in general there is great diversity in attention to quality and no consensus on desirable standards. The diversity of techniques applied for otolith preparation (Christensen 1984, Miller \& Simenstead 1994, Estep et al. 1995, Casselman \& Scott 2000, Easey \& Millner 2008) and microscopy has hampered the adoption of widely agreed protocols with respect to studies of otolith $\mathrm{MaS}$, and the guidelines for image acquisition are typically quite imprecise (e.g. Clausen 2006). While this represents a problem for human interpretation, it is of vital significance for CAAGE systems (Mahé 2009).

It is tempting to think that image acquisition is mainly concerned with camera and sensor technologies, but the considerable improvements in image quality and widespread availability of colour images (e.g. Fig. 2) over the last 2 decades have not translated into similar improvements in overall system accuracies. Some articles demonstrate that surprisingly good images can be obtained at low cost (Campana 1987, Rypel 2008). Modern digital cameras are not prohibitively expensive, and for fisheries that are well resourced, it is unlikely that camera technology will be a limiting factor. Studies undertaken by AFISA used Leica 300/320 digital cameras (3.3 Megapixels, up to 36-bit colour depth) and a stereomicroscope (Leica MZ6). However, they found that factors such as consistent illumination geometry and otolith preparation were important in achieving good overall performance.

Images are essentially just the visual rendering of an array of numbers, representing pixel (picture element) intensities. Computers running image-processing programs make decisions based on individual values in the array. It is essential that these values are reproducible; for example, the same otolith, imaged at a different time, with the same equipment, should yield the same, or very similar values. Even if the computer program interprets relative differences between pixel values, rather than absolute values, it is important that differences in intensities across the image are consistent. Microscopy in most otolith labs tends to be optimised for human readers and the lighting geometry is flexible, allowing it to be easily adjusted for personal preference, per otolith. In contrast, automated systems go to great lengths to ensure lighting geometry is fixed and this is often addressed by establishing calibration protocols. There is some evidence that fisheries science is addressing these issues, driven by a need to meet quality assurance standards. The AFISA project (Mahé 2009) took great care to measure light intensities and adopted a consistent setup protocol. 
Table 1. Computerised age and growth estimation (CAAGE) of otolith macrostructure (MaS) from the published literature (1990 onwards). 1-D = 1-dimensional, $2-\mathrm{D}=2$-dimensional, $\mathrm{ML}=$ machine learning, Prep $=$ otolith preparation, $\mathrm{W}=$ whole, $\mathrm{S}=$ section, $\mathrm{APE}=$ average percent error; dashes indicate data not available. VI-A: ICES area

\begin{tabular}{|c|c|c|c|c|c|c|c|c|c|}
\hline \multirow[t]{2}{*}{ CAAGE classification } & \multicolumn{3}{|c|}{ Method } & \multirow[t]{2}{*}{ Species } & \multirow[t]{2}{*}{ Area } & \multirow[t]{2}{*}{$\mathrm{N}$} & \multicolumn{3}{|c|}{ Evaluation } \\
\hline & $1-\mathrm{D}$ & $2-\mathrm{D}$ & ML & & & & $\begin{array}{l}\text { Age } \\
\text { or size }\end{array}$ & Prep & $\begin{array}{l}\text { APE } \\
(\%)\end{array}$ \\
\hline \multicolumn{10}{|l|}{ Interactive systems } \\
\hline Panfili et al. (1990) & $\checkmark$ & & & Mediterranean eel Anguilla anguilla & - & - & - & $\mathrm{W}$ & - \\
\hline $\begin{array}{l}\text { Cailliet et al. (1996), } \\
\text { King (1993) }\end{array}$ & $\checkmark$ & $\checkmark$ & & Bank rockfish Sebastes rufus & - & 60 & - & $\mathrm{S}$ & 4.0 \\
\hline Benzinou et al. (1997) & & $\checkmark$ & & Plaice Pleuronectes platessa L. & - & - & - & - & - \\
\hline Formella et al. (2007) & $\checkmark$ & $\checkmark$ & & Cod Gadus morhua & $<55^{\circ} \mathrm{N}$ & 17 & $3-5 \mathrm{yr}$ & $\mathrm{S}$ & 14.0 \\
\hline \multicolumn{10}{|l|}{ Fully automatic systems } \\
\hline Troadec (1991) & $\checkmark$ & & & Saithe Pollachius virens & VI-A & 58 & $3-10$ yr & W & 4.3 \\
\hline $\begin{array}{l}\text { Welleman \& } \\
\text { Storbeck (1995) }\end{array}$ & $\checkmark$ & & & Plaice Pleuronectes platessa L. & - & 334 & $2-5$ yr & $\mathrm{W}$ & $\begin{array}{l}3.0- \\
18.0\end{array}$ \\
\hline \multirow{8}{*}{$\begin{array}{l}\text { Robertson \& } \\
\text { Morison (2001) }\end{array}$} & $\checkmark$ & & $\checkmark$ & King George whiting Sillaginodes punctate & - & 378 & $2-5 \mathrm{yr}$ & $\mathrm{S}$ & 3.5 \\
\hline & $\checkmark$ & & $\checkmark$ & School whiting Sillago flindersi & - & 514 & $1-6 \mathrm{yr}$ & $\mathrm{S}$ & 12.3 \\
\hline & $\checkmark$ & & $\checkmark$ & Ling Genypterus blacodes & - & 2226 & $0-17 \mathrm{yr}$ & $\mathrm{S}$ & 18.0 \\
\hline & $\checkmark$ & & $\checkmark$ & Snapper Pagrus auratus & - & 987 & $0-28 \mathrm{yr}$ & $\mathrm{S}$ & 22.2 \\
\hline & $\checkmark$ & & $\checkmark$ & Black bream Acanthopagrus butcheri & - & 913 & $1-37 \mathrm{yr}$ & $\mathrm{S}$ & 17.2 \\
\hline & $\checkmark$ & & $\checkmark$ & Sand flathead Platycephalus bassensis & - & 963 & $0-20 \mathrm{yr}$ & $\mathrm{S}$ & 18.2 \\
\hline & $\checkmark$ & & $\checkmark$ & Blue grenadier Macruronus novaezelandiae & - & 1531 & $1-19 \mathrm{yr}$ & $\mathrm{S}$ & 15.6 \\
\hline & $\checkmark$ & & $\checkmark$ & Ocean perch Heliocolenus sp. & - & 573 & $4-60 \mathrm{yr}$ & $\mathrm{S}$ & 21.8 \\
\hline Troadec et al. (2000) & & $\checkmark$ & & Plaice Pleuronectes platessa L. & - & 102 & $2-5$ yr & $\mathrm{W}$ & 20.0 \\
\hline Takashima et al. (2000) & $\checkmark$ & & $\checkmark$ & White-spotted char Salvilinus leucomaenis & - & 439 & $2-6 \mathrm{yr}$ & $\mathrm{W}$ & - \\
\hline \multirow[t]{2}{*}{ Fablet et al. (2003) } & $\checkmark$ & & & Plaice Pleuronectes platessa L. & Eastern Channel & 116 & $0-6$ yr & - & 40.0 \\
\hline & & & & Plaice Pleuronectes platessa L. & Eastern Channel & 116 & $7-11 \mathrm{yr}$ & - & 10.0 \\
\hline Fablet et al. (2004) & $\checkmark$ & & $\checkmark$ & Plaice Pleuronectes platessa L. & Eastern Channel & 300 & $1-6 \mathrm{yr}$ & - & 14.0 \\
\hline $\begin{array}{l}\text { Fablet (2006b), Fablet } \\
\& \text { Le Josse (2005) }\end{array}$ & $\checkmark$ & & $\checkmark$ & Plaice Pleuronectes platessa L. & Eastern Channel & 320 & $1-6 \mathrm{yr}$ & - & 12.0 \\
\hline Fablet (2006a) & $\checkmark$ & & $\checkmark$ & Plaice Pleuronectes platessa L. & Eastern Channel & 200 & $1-6 \mathrm{yr}$ & - & 11.0 \\
\hline \multirow[t]{2}{*}{ Palmer et al. (2005) } & & $\checkmark$ & & Plaice Pleuronectes platessa L. & - & - & - & - & - \\
\hline & & $\checkmark$ & & Cod Gadus morhua & - & - & - & - & - \\
\hline Courbin et al. (2007) & $\checkmark$ & $\checkmark$ & $\checkmark$ & Hake Merluccius merluccius & - & 628 & $8-50 \mathrm{~cm}$ & W & - \\
\hline \multirow[t]{6}{*}{ Mahé (2009) } & $\checkmark$ & $\checkmark$ & $\checkmark$ & Cod Gadus morhua & North Sea & 311 & 1 to $3+y r$ & $\mathrm{~S}$ & 13.8 \\
\hline & $\checkmark$ & $\checkmark$ & $\checkmark$ & Cod Gadus morhua & Northeast Arctic & 527 & 2 to $7+y \mathrm{r}$ & $\mathrm{S}$ & 25.48 \\
\hline & $\checkmark$ & $\checkmark$ & $\checkmark$ & Cod Gadus morhua & Faroe Plateau & 254 & $1-6 \mathrm{yr}$ & $\mathrm{S}$ & - \\
\hline & $\checkmark$ & $\checkmark$ & $\checkmark$ & Plaice Pleuronectes platessa L. & Eastern Channel & 237 & 2 to $6+y \mathrm{r}$ & $\mathrm{S}$ & 34.16 \\
\hline & $\checkmark$ & $\checkmark$ & $\checkmark$ & Plaice Pleuronectes platessa L. & Iceland & 251 & 4 to $7+y \mathrm{r}$ & $\mathrm{W}$ & 13.06 \\
\hline & $\checkmark$ & $\checkmark$ & $\checkmark$ & Anchovy Engraulis encrasicolus & Bay of Biscay & 312 & 1 to $2+y \mathrm{r}$ & $\mathrm{W}$ & 9.35 \\
\hline Sória Pérez (2012) & $\checkmark$ & & $\checkmark$ & Plaice Pleuronectes platessa L. & & 189 & $2-6$ yr & & 11.5 \\
\hline
\end{tabular}

Fisheries scientists making measurements of opacity using images go to great lengths to ensure their otolith preparation and imaging protocols deliver precise measurements. They favour thinly ground otolith sections under transmitted light (Hüssy \& Mosegaard 2004, Jolivet et al. 2013). The need for consistent lighting geometry mitigates against using whole otoliths, as due to their irregular surface and crystalline structure, the appearance of growth marks is very sensitive to small variations in the lighting geometry. Imaging thin sections has been shown to enhance the contrast between opaque and hyaline zones, illuminated by reflected light (Panfili et al.
1990). AFISA tested their system with both whole otoliths (under reflected light) and transverse and sagittal sections (under both reflected and transmitted light). They used one magnification setting and carefully configured the lighting and ensured consistency by making measurements on a 'calibration otolith'. AFISA found that

'the set-up concerning light settings were [sic] highly influential on the opacity measure and were [sic] very well defined and all measurements of opacity were done using a standard set-up in which the magnification, the light settings, position of light-source and otolith under the light and the setting of the frame-grabber system was [sic] kept constant between all otoliths' (Mahé 2009, p. 15). 

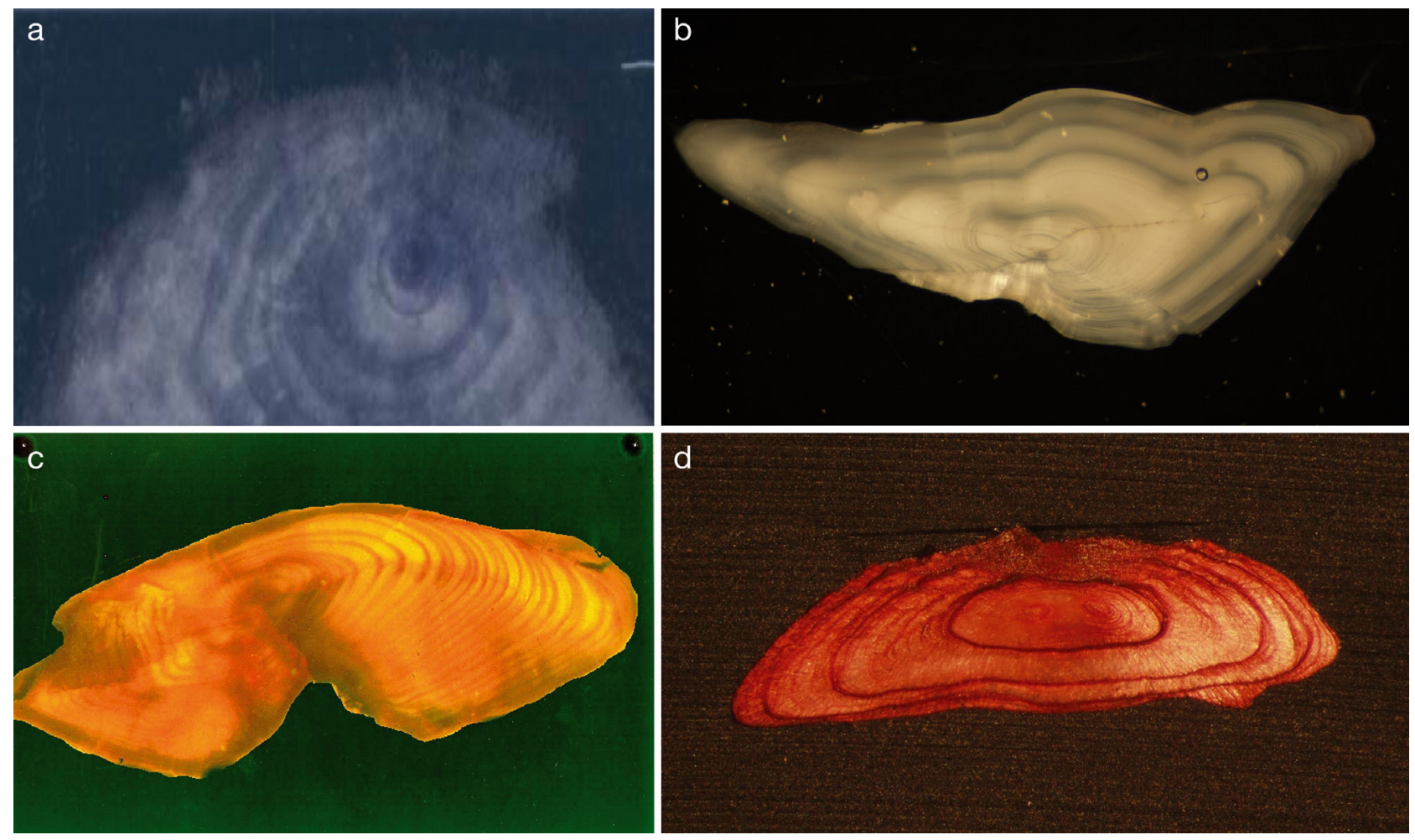

Fig. 2. Example otolith images illustrate improvement in image capture technology: (a) eel Anguilla anguilla, sectioned otolith (Panfili et al. 1990); (b) cod Gadus morhua, sectioned otolith (2013 image from Cefas); (c) eel, sectioned otolith stained with neutral red (2013 image from Cefas); (d) sole Solea solea, sectioned otolith stained with neutral red (2013 image from Cefas)

\section{Image processing}

Image processing is mostly concerned with digital processing of signals derived from images. The techniques employed can be classified as low-level, e.g. enhancement of contrast, noise removal, and thresholding; and high-level, e.g. image/object classification, and scene understanding (Sonka et al. 2008, Gonzalez \& Woods 2008). The term 'computer vision' is used to describe systems that perform high-level tasks and exhibit intelligent behaviour. Computer vision systems often take advantage of temporal coherence between video frames rather than working with one isolated image. Almost all computer vision systems employ computer software, and developing efficient pattern-recognition algorithms is very much a focus of current research. Image-based CAAGE techniques can be broadly classified as 1-D or 2-D, and a good overview of these is provided by Troadec \& Benzinou (2002). 1-D approaches measure the opacity profile along a line originating at the otolith core and ending at the edge (Panfili et al. 1990, Troadec 1991, Welleman \& Storbeck 1995). This line is called a ray or transect and is usually taken in the direction of maximal growth; an example is shown in Fig. 3. In contrast, 2-D approaches consider all the otolith's pixels rather than just those that underlie one (or a small number of) transect(s). A 2-D approach is essential for some algorithms, such as finding the position of the core or nucleus, but other operations such as filtering the image may be accomplished equivalently in 1-D or 2-D. One of the most common image-processing operators used in CAAGE is a smoothing filter. Many otolith readers interactively apply filters to improve the distinction between increments and will be familiar with the names used to identify the kernels (e.g. 'Laplacian', 'unsharp' etc.). These enhance fine detail, but often amplify image noise. Fortunately, humans are good at discriminating between structured and unstructured visual information and can discount the noise. But, unlike humans, computers are unable to discriminate between structured high-frequency information and noise, so high frequencies are usually suppressed by applying a smoothing filter prior to processing. AFISA highlighted some challenges in applying smoothing filters to otolith images. Firstly, the ring structures are clearly oriented, and secondly, 

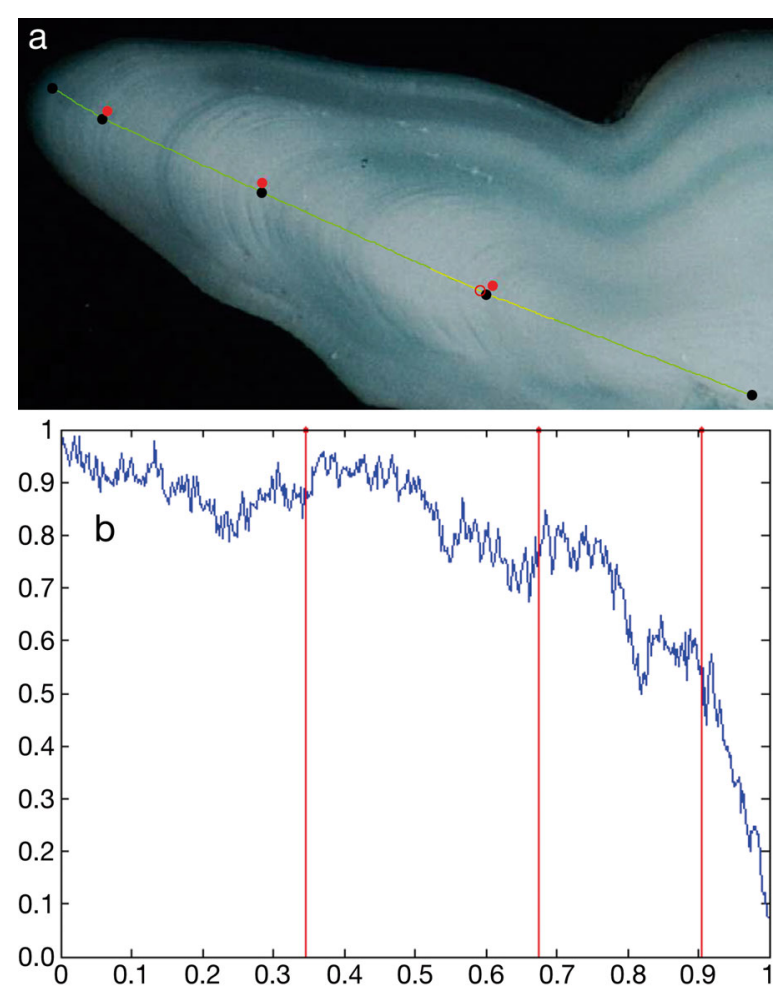

Fig. 3. (a) Section of a 3 yr old cod otolith. Red dots, from left to right: the nucleus and successive year marks, placed manually by an expert. Yellow/green line: the radial transect used to extract the intensity profile. Black dots denote positions where growth marks identified by red dots intersect the radial transect. Open red circle: position of the computed first annual ring along this intensity profile. (b) Intensity profile along the radial growth axis. Note: $X$-axis shows relative distance from otolith nucleus, $y$-axis shows pixel intensity $(0.0=$ black, $1.0=$ white $)$. Vertical red lines denote positions of black dots shown in panel (a). From Mahé (2009)

their width is modulated by the growth function. Further, the opaque and translucent rings are also associated with different scales. These factors make optimising the filter parameters very difficult. AFISA addressed this by employing a novel filter that used a 2-D otolith growth model (discussed in the section '2-D analysis') to automatically adapt its parameters in different regions of the otolith image.

\section{1-D analysis}

The first algorithms for automatically ageing otoliths simply enumerated the peaks in a 1-D transect opacity signal (Panfili et al. 1990), but more robust results are obtained using Fourier analysis to digitally process the signal (Troadec 1991). Troadec demodulates the transect signal by assuming otolith growth to be modelled by a 1-D growth function and then uses Fourier analysis to establish the fish age. Welleman \& Storbeck (1995) consider the problem of automatically identifying the nucleus and evaluate their system for routine ageing of 334 plaice Pleuronectes platessa individuals. Extending this work, other researchers have exploited alternative signal processing techniques such as wavelet decomposition (Morales-Nin et al. 1998, Palmer et al. 2005) and bilinear transforms (Fablet et al. 2003) to study the time-frequency signal behaviour. Both Troadec (1991) and Formella et al. (2007) apply coordinate transformations before processing; an example is shown Fig. 4. Fig. 4b,c illustrates problems associated with non-uniform growth that in turn give rise to local discontinuities. To address problems that arise due to differences in accretion rates that (in extreme cases) can give rise to local discontinuities in 1-D signals representing growth rings, Troadec (1991) integrates profiles using a median estimator to improve robustness and Campana (1992) proposed combining measurements from different sources. Takashima et al. (2000) combine information from 1-D transects in a statistical model, while Guillaud et al. (2002a,b), Rodin et al. (1996) and Palmer et al. (2005) describe algorithms linking growth features in adjacent transects, thereby providing a step towards 2-D analysis.

\section{2-D analysis}

In the late $1990 \mathrm{~s}$, researchers attempted to use 2-D image segmentation tools called active contour models to recover complete growth rings. The approach is inspired by a computational analogue of an elastic band that is seeded in the image and allowed to deform due to external forces generated by image features (e.g. annular rings). The contour is free to move, finally reaching equilibrium when the internal elastic force in the model and the external image features are balanced. The internal force comprises several parameterised components that can be tuned to ensure the contour remains smooth and unbroken even when the external image features are weak, so that the contour is robust to cases where the annular growth marks are incomplete. Sethian's work on evolving interfaces (Sethian 1996) provides an efficient mathematical framework for this type of model, and Troadec et al. (2000) use this to recover 2-D growth features. The model aims to generate the arrival time surface, $T(x, y)$, shown in Fig. 5, that in turn is interpreted as a forward model of growth. Using this surface, the otolith ring structures are predicted by solving the equation 

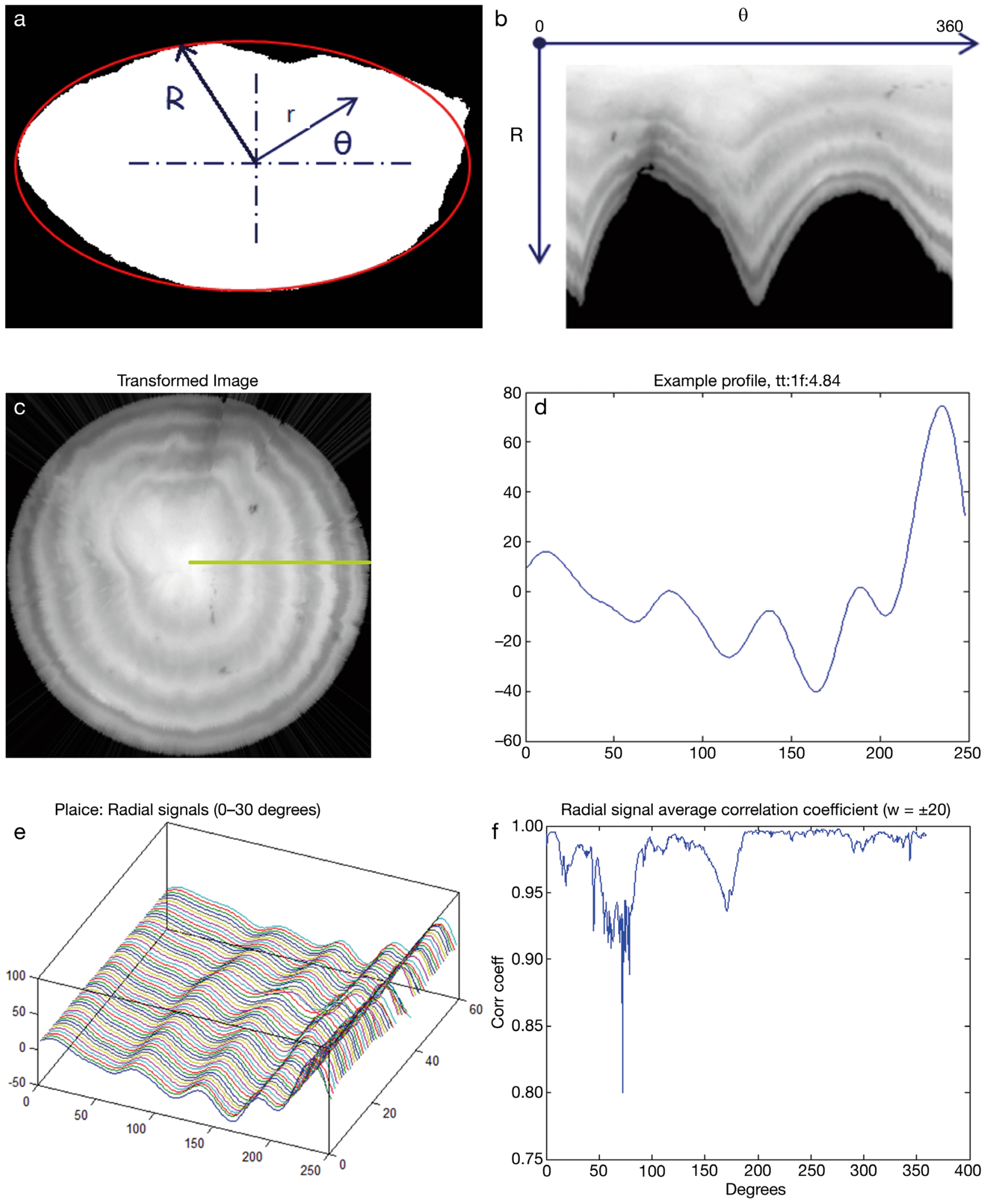

Fig. 4. (a) Plaice (Pleuronectes platessa) otolith binary image illustrating Cartesian to polar transform $P(r, \theta)$ where $r=$ $\sqrt{x^{2}+y^{2}}, \theta=\tan ^{-1} y / x$; (b) transformed plaice otolith $P(r, \theta)$; (c) rescaled polar transformation $P\left(r^{t}, \theta\right)$ where $r^{t}=r / R ;(d)$ filtered radial 1-dimensional (1-D) transect signal (path highlighted in green in (c)); (e) ensemble of 1-D transects $\left(0-30^{\circ}\right)$; (f) covariance between neighbouring 1-D transects 


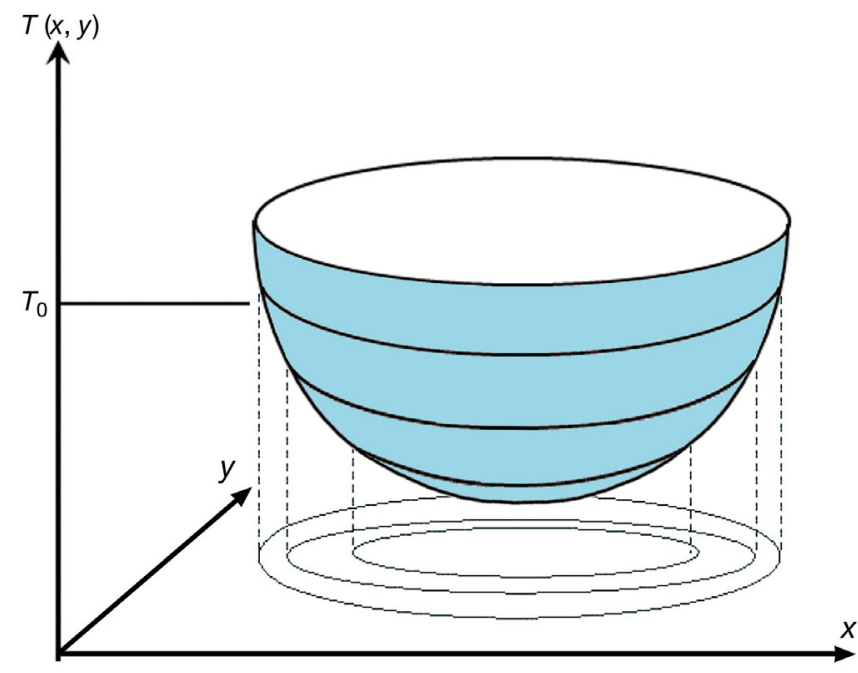

Fig. 5. The arrival time surface $T(x, y)$ in relation to observed otolith ring structures

$$
T(x, y)=T_{0}
$$

for any $T_{0}$. The solution of this equation corresponds to the otolith surface at time $T_{0}$, and further embedded growth layers at $t>T_{0}$, thereby allowing a time series of otolith shapes to be synthesised. AFISA (Mahé 2009) adopted and extended this model by combining low-level growth cues derived from the local orientation and shape of growth marks (Álvarez et al. 2008, Chessel et al. 2008, Fablet et al. 2008, 2009). The accuracy of this forward model of accretionary otolith morphogenesis in space and time is illustrated in Fig. 6. The model is used by AFISA to drive the adaptive smoothing filter introduced in the section 'Image processing' above, but more recently it has been extended to form the basis for more complex bioenergetic models (Fablet et al. 2011).

An important subproblem for both 1-D and 2-D approaches is that of detecting the otolith nucleus or core; this is the focus of work by Cao \& Fablet (2006). They combine morphological features recovered from the otolith image and a statistical model trained on expert readers to automatically locate the otolith core. Machine learning is a paradigm that seems to deliver the best results in terms of performance for automatic ageing, and neural network and statistical frameworks are popular implementations. Approaches that use machine learning paradigms often derive features from spatial and frequency domain analysis of 1-D transect signals, sometimes combined with 2-D features extracted from the image (Robertson \& Morison 1999, Fablet et al. 2004, Fablet \& Le Josse 2005, Fablet 2006a) and other measurements such as weight (Fablet 2006b, Bermejo 2007).

Since 2010, there has been a noticeable shift towards computational modelling of otolith increment formation through integration of visual and chemical analysis. These efforts have attempted to answer questions relating to the coupling between otolith growth and fish growth through metabolism and the formation of opaque and translucent growth zones in relation to the physiology of the individual (Grønkjaer 2016).

\section{VALIDATION OF COMPUTER-ASSISTED OTOLITH ANALYSIS}

Troadec \& Benzinou (2002) review the motivation for pursuing research into CAAGE systems, citing improvements in accuracy, precision, and productivity. While early research tended to evaluate the accuracy of computer-assisted and automatic ageing systems with reference to human interpretation and give results in terms of absolute error $(\Delta)$, more recent studies use methods that report errors in the context of amongst-reader variability. A recent evaluation by Fablet (2006b) (plaice Pleuronectes platessa otoliths, $\mathrm{N}=320$ ) reported $95 \%$ of automatic age estimates were identical to those of human readers, and Takashima et al. (2000) claimed the performance of automated counting to be indistinguishable
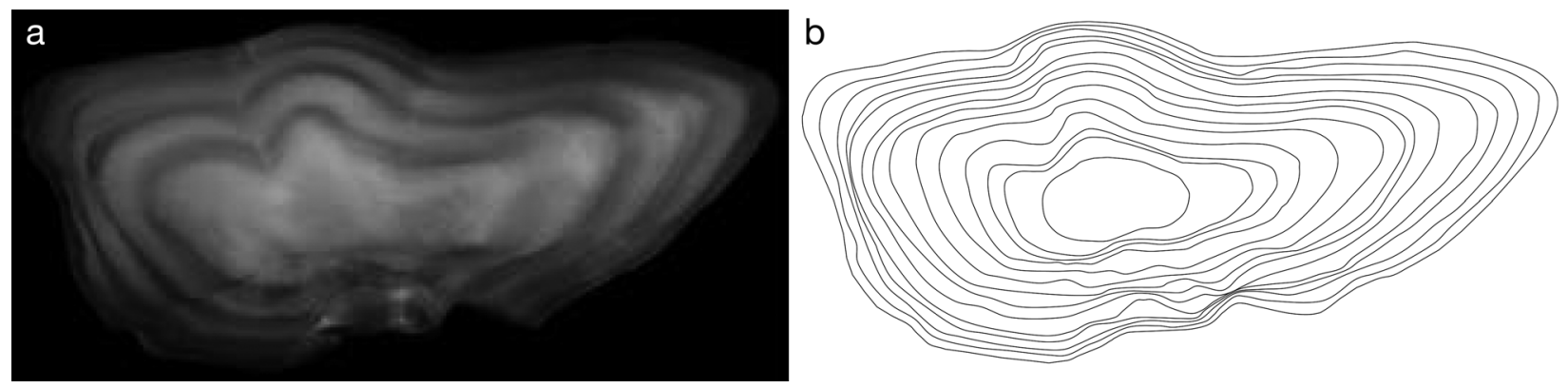

Fig. 6. (a) Cod otolith image (transverse section) rendered by overlaying annular growth rings, generated by forward growth model (b) 
to that of expert readers. The precision (the ability of a system to produce repeatable measurements) of computer-assisted techniques has been reported to be similar to that of human interpretation (Cailliet et al. 1996), and broad agreement exists that the benefit from computational recording of results lies in the elimination of minor errors in the process. Troadec \& Benzinou (2002) argue that using a computerised process forces readers to focus their attention on a defined protocol, and this in turn produces benefits in terms of quality assurance. With this in mind, some laboratories have written species-specific protocols for age analysis that require the users to execute (ImagePro) macros defining sequences of imageprocessing functions. An ImagePro plug-in developed by Alaska fisheries is available from www. mediacy.com/resources/appcenter/otolith-application-27-detail. The question of productivity is frequently addressed. Developers of interactive systems claim a benefit (from 30-300\% depending on the task) in using computer-assisted techniques, while developers of fully automated systems (e.g. Troadec \& Benzinou 2002) conclude that the prospect of fully automated unsupervised processing (of a subset of fish species) is entirely feasible. AFISA (Mahé 2009) undertook a very detailed evaluation of the technology, and their findings are summarised in the next section.

Since 2010, most work on automated ageing has been focused on evaluating and improving models that use otolith morphology, sometimes combined with biological measurements, for stock assessment (Smith \& Campana 2010, Matic-Skoko et al. 2011, Campana \& Fowler 2012, Bermejo 2014, Williams et al. 2015). Some of this work is motivated by a need to manage stock in artisanal fisheries located in areas where there is a shortage of trained readers. Although the accuracy of morphometric approaches is poorer than estimates provided by human readers, some scientists conclude that, with hindsight, there would have been little difference in stock management strategies, had previous decisions been based on ages derived from morphometric rather than expert estimates (Williams et al. 2015).

\section{COST-BENEFIT ANALYSIS}

The most significant research effort in recent years to assess CAAGE applications in otolith reading was the AFISA project (Mahé 2009). AFISA attempted to address the cost of using age-based models based on age estimations using otolith read- ings, considered to be several million euros annually, by using automated computerised techniques. In this context, the project aimed to provide a means of standardising ageing amongst laboratories and to build interpreted image databases that could, in turn, be used for quality assurance as well as reducing the cost of acquiring age data. AFISA developed and tested a suite of algorithms for imagebased CAAGE. Some of these have been reviewed earlier in this article, but although results testing the accuracy of various systems ageing plaice were published (Table 1), the wider picture resulting from a detailed cost-benefit analysis comparing the performance of several different CAAGE systems and otolith reading across a range of fisheries has until now only been accessible as a final project report (Mahé 2009). The project evaluation focused on 3 case studies (Table 2): cod Gadus morhua (Faroe Plateau, North Sea, and northeast Arctic); anchovy Engraulis encrasicolus (Bay of Biscay); and plaice Pleuronectes platessa (Eastern Channel and Iceland). A total of 6729 otoliths were collated from surveys and commercial landings, and the following associated data were recorded: area, year, quarter, total length, weight, sex, and maturity. Two different approaches delivering automated age estimates were evaluated (Table 3): using 1-D opacity profiles along radial transects, and a conditional model using morphologic descriptors together with a nearest-neighbour classifier. These were compared with another morphologic approach using a mixture model (Francis \& Campana 2004) and estimates by expert readers. The evaluation method built agelength keys for each approach based on a subset of each fish stock from the database. The efficiency or precision of a method is determined by the goodness-of-fit of the age-length key built from a subset compared to the true age distribution of the sample. Results from 3 case studies (cod, plaice, and anchovy) undertaken by AFISA are presented in Table 3. The analysis only considered a homogeneous subset of fish (i.e. individual fish data for which the relationship between age, length, otolith weight and other otolith characteristics is the same) caught in the same year and quarter (Table 2). The costs (Table 4) were estimated from work undertaken within the project. As all the automatic methods required experts to prepare training sets of otoliths, manual age reading remained an essential component. The cost of both the morphological and image-based automated methods are considered as equivalent, the major component of cost being due to the preparation of otolith samples. The accuracy 
Table 2. Automated FISh Ageing (AFISA) case study samples (Mahé 2009). Cefas $=$ Centre for Environment, Fisheries and Aquaculture Science (UK), IMR = Institute of Marine Research (Norway), Difres = Danish Institute for Fisheries Research, Ifremer = Institut Français de Recherche pour l'Exploitation de la Mer (France), MRI = Marine Research Institute (Iceland), AZTI = AZTI Technology Centre (Spain), NS = North Sea, NEA = northeast Arctic, FP = Faroe Plateau, $\mathrm{EC}=$ Eastern Channel (ICES area VIId), Biscay $=$ Bay of Biscay, Prep $=$ otolith preparation, $\mathrm{W}=$ whole, $\mathrm{S}=$ section. Faroe samples collected by the Fish Ageing by Otolith Shape Analysis (FAbOSA) project (Arneri et al. 2002)

\begin{tabular}{|lccccccc|}
\hline \multicolumn{2}{l}{ Institute Species } & Area & Year & Quarter & Source & Prep & N \\
\hline Cefas & Cod & NS & 1998 & 3 & Survey & S & 400 \\
Cefas & Cod & NS & 1999 & 3 & Survey & S & 347 \\
Cefas & Cod & NS & 2000 & 3 & Survey & S & 400 \\
Cefas & Cod & NS & 2001 & 3 & Survey & S & 400 \\
IMR & Cod & NEA & 2000 & $1-4$ & Survey & S & 494 \\
IMR & Cod & NEA & 2001 & $1-4$ & Survey & S & 498 \\
IMR & Cod & NEA & 2004 & $1-4$ & Survey & S & 500 \\
IMR & Cod & NEA & 2005 & $1-4$ & Survey & S & 500 \\
Difres & Cod & FP & $1996-2001$ & $1-4$ & Tag/recapture & S & 255 \\
Ifremer & Plaice & EC & 2006 & 1 & Survey/market & W/S & 248 \\
Ifremer & Plaice & EC & 2006 & 2 & Survey/market & W/S & 249 \\
Ifremer & Plaice & EC & 2006 & 3 & Survey/market & W/S & 195 \\
Ifremer & Plaice & EC & 2006 & 4 & Survey/market & W/S & 237 \\
MRI & Plaice & Iceland & 2006 & $1-4$ & Market & W & 1000 \\
AZTI & Anchovy & Biscay & 1998 & $1-3$ & Market & W & 500 \\
AZTI & Anchovy & Biscay & 1999 & $1-3$ & Market & W & 500 \\
AZTI & Anchovy & Biscay & 2004 & 2 & Market & W & 500 \\
AZTI & Anchovy & Biscay & 2005 & $1-3$ & Market & W & 500 \\
\hline
\end{tabular}

of each method is given in terms of mean-squared error (MSE) and relative bias (Table 3), computed as follows:

'For a given stock and period, usually a quarter, data on fish length and weight, otolith characteristics such as weight, area etc. and the age determined by expert readers were available for a random sample of fish. This sample was randomly divided into two groups of equal size, for which one group was used as learning data with the age included and the second was used as testing data for which the age information were [sic] excluded. For each of the three methods the age distribution in the combined learning and testing sample (i.e. the original random sample available) was estimated based on these data. This procedure was repeated 100 times and thus resulting [sic] in 100 estimates of the age distribution in the combined learning and testing sample. As the 'true' age distribution is known in this combined sample the goodness of the methods can be evaluated' (Mahé 2009, p 120).

Since the true age-length key is built using otolith ages provided by expert readings for the whole sample, the results for age-length key (i.e. age determined by expert readers) given in Table 3 reflect the sampling error. MSE is the most important since it measures the mean error across all ages. Relative bias provides information about how the errors are distributed.
For example, a high relative bias indicates that the error is not normally distributed and the system shows a tendency to under- or over-estimate a particular year group. It is important to note that bias can exist for the age estimation among international readers. For example, exchanges of Arctic cod otoliths have also reported interreader bias, indicating that there are significant differences in age estimates among readers from different institutions (Yaragina et al. 2009, Healey et al. 2011).

The results presented in Table 3 show that the mixture model (Francis \& Campana 2004) outperforms the nearest-neighbour classifier built on morphometric features and gives an MSE close to that of expert readers. The performance of image-based CAAGE gives at best an MSE between 5 and 10 times greater than expert readers (often more for particular year groups). We discuss these results in the next section.

\section{DISCUSSION}

\section{Computer vision, image processing and image quality}

Computer vision technology has matured over the last 3 decades and is now commonly deployed by manufacturing industries to guide robotic systems, inspect component parts or complete assemblies, etc. These will usually have been precisely manufactured often by numerically controlled machines using data derived from computer-aided design (CAD) software. The lighting within manufacturing cells that use these systems is tightly controlled and conventional camera images are often supplemented by additional sensors (e.g. lasers). More challenging scenarios for computer vision lie in specific applications that are less constrained but which are the subject of well-documented domain ontologies. Otolith ageing represents an important application and an opportunity to benchmark intelligent systems that integrate computer vision and machine learning. The importance of this research within the image analysis and machine learning community is evidenced by the many articles published in relevant computer- 
Table 3. Automated FISh Ageing (AFISA) case study: mean squared error (MSE) and relative bias (RB) by method, stock and age (Mahé 2009). Note: MSE and RB are calculated using the methodology described by Mahé 2009 (p. 121). (-) not determined (Mahé 2009)

\begin{tabular}{|c|c|c|c|c|c|c|c|c|c|}
\hline \multirow[t]{3}{*}{ Stock } & \multirow{3}{*}{$\begin{array}{l}\text { Age } \\
(y r)\end{array}$} & \multirow{2}{*}{\multicolumn{2}{|c|}{ — Automated — }} & \multirow{2}{*}{\multicolumn{2}{|c|}{${ }_{-}$Conditional ${ }^{-} \mathrm{Me}$}} & \multirow{2}{*}{\multicolumn{2}{|c|}{$\begin{array}{l}\operatorname{hod}-\text { Francis } \&- \\
\text { Campana }(2004)\end{array}$}} & \multirow{2}{*}{\multicolumn{2}{|c|}{$\begin{array}{c}\text { Age-length } \\
\text { key }\end{array}$}} \\
\hline & & & & & & & & & \\
\hline & & MSE $(\times 100)$ & Bias (\%) & MSE $(\times 100)$ & Bias (\%) & MSE $(\times 100)$ & Bias $(\%)$ & MSE $(\times 100)$ & Bias (\%) \\
\hline \multirow{3}{*}{$\begin{array}{l}\text { North Sea } \\
\operatorname{cod}(\mathrm{N}=311)\end{array}$} & 1 & 0.40 & 4.47 & 0.66 & 1.65 & 0.23 & -0.88 & 0.31 & -0.22 \\
\hline & 2 & 4.04 & 8.68 & 0.71 & 0.92 & 0.36 & -0.34 & 0.36 & -0.25 \\
\hline & $3+$ & 4.44 & -100.0 & 0.21 & -14.77 & 0.12 & 5.67 & 0.12 & 2.92 \\
\hline \multirow{6}{*}{$\begin{array}{l}\text { Northeast Arctic } \\
\operatorname{cod}(\mathrm{N}=527)\end{array}$} & $2-$ & 1.02 & -67.64 & 0.58 & -46.84 & 0.06 & 10.73 & 0.02 & 1.06 \\
\hline & 3 & 1.47 & -18.39 & 0.32 & -1.02 & 0.17 & -3.14 & 0.16 & 1.04 \\
\hline & 4 & 8.32 & 31.35 & 0.87 & 7.86 & 0.34 & 2.6 & 0.25 & -0.42 \\
\hline & 5 & 2.83 & 19.54 & 1.09 & 11.52 & 0.22 & -1.12 & 0.33 & -0.81 \\
\hline & 6 & 0.70 & -1.37 & 0.41 & -2.51 & 0.16 & -0.77 & 0.22 & 0.13 \\
\hline & $7+$ & 4.12 & -51.58 & 0.69 & -13.74 & 0.09 & -1.61 & 0.15 & 0.15 \\
\hline \multirow{6}{*}{$\begin{array}{l}\text { Faroe Plateau } \\
\operatorname{cod}^{\mathrm{a}, \mathrm{b}}(\mathrm{N}=254)\end{array}$} & 1 & - & - & 0.93 & -17.31 & - & - & 9.32 & 1.48 \\
\hline & 2 & - & - & 2.52 & -13.81 & - & - & 3.47 & 0.67 \\
\hline & 3 & - & - & 1.25 & 12.03 & - & - & 1.25 & 0.07 \\
\hline & 4 & - & - & 1.65 & -16.68 & - & - & 6.71 & -0.27 \\
\hline & 5 & - & - & 2.62 & 35.29 & - & - & 1.30 & -0.70 \\
\hline & 6 & - & - & 2.17 & 31.63 & - & - & 1.30 & -0.17 \\
\hline \multirow{5}{*}{$\begin{array}{l}\text { Eastern Channel } \\
\text { plaice }(\mathrm{N}=237)\end{array}$} & $2-$ & 0.45 & -12.81 & 2.69 & -38.69 & 0.19 & 6.36 & 0.28 & 0.37 \\
\hline & 3 & 2.13 & 21.96 & 2.27 & 13.36 & 0.47 & -2.44 & 0.52 & -0.51 \\
\hline & 4 & 2.24 & -6.19 & 1.93 & -11.01 & 0.56 & -3.33 & 0.58 & -1.08 \\
\hline & 5 & 21.3 & 53.73 & 6.20 & 24.71 & 0.74 & -0.79 & 0.78 & 0.92 \\
\hline & $6+$ & 21.1 & -49.91 & 2.25 & -10.13 & 0.56 & 1.85 & 0.59 & -0.02 \\
\hline \multirow{4}{*}{$\begin{array}{l}\text { Icelandic plaice } \\
(\mathrm{N}=251)\end{array}$} & $4-$ & 1.28 & -35.56 & 1.68 & -31.00 & 0.28 & -3.26 & 0.21 & 1.14 \\
\hline & 5 & 0.63 & -6.77 & 2.62 & -19.57 & 0.59 & 3.86 & 0.43 & -0.31 \\
\hline & 6 & 6.09 & 16.70 & 2.88 & 7.88 & 0.89 & -0.30 & 1.09 & 0.72 \\
\hline & $7+$ & 1.96 & -5.83 & 2.26 & 5.30 & 0.71 & -0.49 & 1.09 & -0.84 \\
\hline \multirow{2}{*}{$\begin{array}{l}\text { Bay of Biscay } \\
\text { anchovy }(\mathrm{N}=312)\end{array}$} & 1 & 3.44 & 7.23 & 29.26 & 23.22 & 0.43 & -1.69 & 0.32 & 0.35 \\
\hline & 2) $2+$ & 2.94 & -13.94 & 29.26 & -53.60 & 0.43 & 3.92 & 0.32 & -0.82 \\
\hline \multicolumn{10}{|c|}{$\begin{array}{l}{ }^{\mathrm{a}} \text { The contrast between transparent and opaque zones was too low for automatic zone detection } \\
{ }^{\mathrm{b}} \mathrm{A} \text { requirement for the Mixture analysis (Francis \& Campana 2004) is that otolith weight and fish length data are normally } \\
\text { distributed within ages. Data from the Faeroe cod stock violated this requirement and Mixture analysis was therefore not } \\
\text { possible }\end{array}$} \\
\hline
\end{tabular}

vision journals (Caselles et al. 1998, Guillaud et al. 2002a,b, Cao \& Fablet 2006) and presented at conferences (Rodin et al. 1996, Benzinou et al. 1997, Fablet et al. 2003, Fablet 2005, Chessel et al. 2006). Most research into automated image-based CAAGE undertaken in the 2000s was funded by the European Union, and the emphasis probably reflected the broader information and communication technology (ICT) research and development (R\&D) agenda that existed at that time in the EU.

Image quality is a decisive factor for image-based automatic ageing systems. Attempts to acquire and measure growth rings using other sensors have either failed, or are too costly to use in production

Table 4. Automated FISh Ageing (AFISA) case study: costs in euros $(\Leftrightarrow)$ per fish for measuring fish characteristics (Mahé 2009). NS $=$ North Sea, NEA = northeast Arctic, FP = Faroe Plateau, EC = Eastern Channel, Biscay = Bay of Biscay, $(-)$ not determined

\begin{tabular}{|c|c|c|c|c|c|c|}
\hline \multirow[t]{3}{*}{ Process } & \multicolumn{6}{|c|}{ Cost $(€)$ per otolith } \\
\hline & \multirow{2}{*}{$\mathrm{NS}$} & \multicolumn{2}{|c|}{$-\operatorname{Cod}-$} & \multicolumn{2}{|c|}{ — Plaice $\_$} & \multirow{2}{*}{$\begin{array}{c}\text { Anchovy } \\
\text { Biscay }\end{array}$} \\
\hline & & NEA & FP & $\mathrm{EC}$ & Iceland & \\
\hline Measuring length and weight and manual age reading & 2.81 & 5.88 & 2.85 & 2.13 & 5.37 & 6.5 \\
\hline Automated age determination and manual age reading & 3.93 & 10.46 & 5.61 & 2.47 & 6.24 & 9.71 \\
\hline Automated age determination & - & - & - & 1.38 & 3.03 & 7.74 \\
\hline Tag/recapture and pen rearing & - & - & 17.0 & - & - & - \\
\hline
\end{tabular}


(Hamrin et al. 1999, Jolivet et al. 2008, 2013, Mapp et al. 2016). AFISA's (Mahé 2009) image acquisition protocol used otolith sections for cod and Eastern Channel plaice and whole otoliths for Icelandic plaice and anchovy, consistently imaged at one magnification. They tested using reflected and transmitted light and carefully set up their system with a calibration otolith. AFISA were unable to obtain age estimates for some stocks due to poor contrast (e.g. Faroe Plateau cod), and found that although images recovered from whole otoliths suffer from instability due to lighting inconsistencies, ages could be automatically estimated from 1-D transects (Mahé 2009). However, more successful outcomes were obtained from digitised images exhibiting clear annual growth structures, such as those acquired from North Sea cod, Icelandic plaice and Eastern Channel plaice (year groups $<5 \mathrm{yr}$ ).

\section{The need for further work}

The literature on image-based CAAGE of otolith MaS since 1990 is summarised in Table 1. While many authors describe image-processing approaches and algorithms for image-based CAAGE of otolith MaS, few studies evaluate performance on a significant cohort of fish $(\mathrm{N}>30)$. The most comprehensive studies involving multiple species have been undertaken by Morison et al. (1998), Robertson \& Morison (1999, 2001) and Mahé (2009). Both use information from 1-D transects. Robertson and colleagues (Morison et al. 1998, Robertson \& Morison 1999, 2001) include this information as an additional feature and show that its inclusion slightly improves the performance of a neural network trained using only morphological and biological features. They use Fourier transforms to encode features of 5 transect signals and test 3 neural network architectures, showing that all deliver similar performance (note: results shown in Table 1 are obtained from a simple back-propagation network trained using only transect signals, i.e. morphological or biological features have been excluded).

The results from AFISA have been published in the form of an EU report only (Mahé 2009), although a subset of the work concerning Eastern Channel plaice feature widely in publications by Fablet and colleagues (Fablet 2005, 2006b, Fablet \& Le Josse 2005). AFISA also analyse transect signals but employ a statistical framework and more complex pre-processing than do Robertson and colleagues (Morison et al. 1998, Robertson \& Morison 1999, 2001). Both systems are automatic, but adopt differ- ent strategies for choosing a suitable set of transects and finding the otolith nucleus. Overall, AFISA's results are consistent with those of Morison et al., but evaluations often highlight problems of undercounting and coping with marginal rings, and this seems to be reflected in high bias for year groups $>3 \mathrm{yr}$. AFISA also highlight problems due to under-represented year groups in the training set for some stocks, resulting in high relative bias. North Sea cod, Icelandic plaice and Bay of Biscay anchovy exhibit the lowest average percent errors. Results from image-based CAAGE using whole otoliths are surprisingly good (e.g. Icelandic plaice and Bay of Biscay anchovy), and could potentially deliver a cost benefit. Although Eastern Channel plaice exhibit high-contrast growth marks, the results suffer from high relative bias (year groups 5 to $6+$ ), and the average percent error found by AFISA is much poorer than that reported in previous studies published by Fablet and colleagues, which seems to suggest that some of these systems combine image-based and morphological information (Fablet 2006b).

While Morison et al. aim to integrate visual and morphological features, AFISA's primary focus is on visual analysis. However, their tests benchmarking against other approaches employing morphological features show that age estimates produced using the mixture model proposed by Francis \& Campana (2004) are consistently better than either of the 2 CAAGE approaches developed by AFISA, and deliver estimates close to those achieved by experts. However, neither technique is applicable for Faroe Plateau cod due to either poor contrast or nonnormally distributed data. This may be because the Faroe Plateau cod data were derived from a tag/ recapture sample, i.e. fish were reared in captivity, tagged, released and subsequently recaptured at different times of the year (Doering-Arjes et al. 2008).

In other domains such as medicine and remote sensing, the availability of open-access, online databases, ground-truthed data and algorithms has motivated considerable interest amongst the computer-vision research community and has generated a valuable and voluminous portfolio of published studies. We suggest therefore that publication of the AFISA database as an online resource could act as a significant catalyst to progress CAAGE-based otolith research.

\section{Cost}

Costs for human and machine ageing systems are broadly similar since a large part of the cost is associ- 
ated with preparing the otolith sections. Some costs shown in Table 4 assume that the cost for both morphometric and image-based systems are equal and that they do not include capital equipment. This is an oversimplification, and it may be reasonably expected that costs for imaging may be slightly higher, given that the process developed by AFISA is computationally demanding. All methods need to be trained using expert reader estimates and assume that there are an equal number of otolith samples in training and production samples. Further work is needed to evaluate the relationship between performance and training. The power of an automated approach lies in the ability to scale, and in a successful system, an adequate performance using as few as $<10 \%$ of the number of production otoliths might be anticipated.

\section{Is age reading too difficult a problem?}

At first sight, otolith reading represents an ideal candidate for a computer vision system, since the application offers a natural progression for state-of-theart algorithms, which by the early 2000s had chalked up some successes on similar but less demanding applications. But, some features of otolith reading present difficulties to the designer of an image-processing algorithm. Firstly, the task is much more challenging than a naïve description in terms of a cyclic pattern of rings suggests. For example, Chauvelon \& Bach (1993) observe that many otoliths are difficult for expert readers to interpret and it is not always possible to age fish along a predefined axis. Secondly, the structure of visual features comprising internal growth marks is complex, comprising check or stress marks in addition to opaque and translucent bands (e.g. Smith 2014, Hüssy et al. 2016b), and although the domain ontology is well defined (Kalish et al. 1995), the expertise needed to successfully interpret growth marks is sometimes related to specific stocks and held within specific institutes. For example, Faroe Plateau cod form a transparent 'winter ring' which is out of phase with the annual cycle, and depending on the time of year that the fish was captured, the final ring has either to be counted or neglected. The accuracy of age estimates from a reader unfamiliar with the Faroe cod stock is only $40-50 \%$, while the equivalent figure is $95-99 \%$ for expert Faroe readers (Doering-Arjes et al. 2008).

AFISA represents the most recent comprehensive attempt to implement and evaluate a CAAGE system. Here we provide a glimpse only of AFISA's case studies; however, the project report describes $>15$ separate algorithms, tested in MATLAB and implemented in $\mathrm{C}$ code within Ifremer's TNPC platform (Fablet \& Ogor 2005). The executive summary of the AFISA project highlights the success of the project and concludes:

'the AFISA project resulted in advances in computer vision which provide more reliable methods to extract information from otoliths in order to estimate the individual age and the age structure. These methods are operational using TNPC software. However, such methods should not be seen as being able to fully substitute to experts. They should rather be seen as tools to provide automatically extracted information that requires a subsequent control by experts for the estimations of individual age and age structure. For some species such as plaice, these methods could be usable from the perspective of bias and costs' (Mahé 2009, p. 7).

With hindsight, perhaps AFISA's goals were overambitious and the decision to include species such as Faroe Plateau cod unwise, since the challenges of reading these stocks are well documented. As a rule of thumb, automated image analysis systems rarely outperform human experts and one would anticipate problems for tasks that attract a high degree of inter-expert variation. The study concludes that results obtained from plaice and North Sea cod which exhibit higher-contrast annular rings would be usable and highlights the importance of ensuring all year groups are equally represented in the training set. Anchovy is also highlighted as a possible candidate for further work due to the potential cost saving. The performance achieved by the mixture model is a major problem for CAAGE and perhaps the reason why this has been the focus of much of the work since 2010.

\section{Future directions for image-based CAAGE}

With the above in mind, there are 2 possible directions for future image-based CAAGE developments in relation to fisheries management and assessment. The first of these lies in adapting the integrated system proposed by Robertson \& Morison (2001) and exploring frameworks for fusing morphological and image-based otolith features. Robertson \& Morison (2001) show this approach boosts performance in the context of a neural network classifier, and if the information from a transect, perhaps positioned interactively, was integrated with the mixture model proposed by Francis \& Campana (2004), then for plaice and cod (Table 3 ) it could conceivably deliver accuracies that are indistinguishable from those of human expert readers. 
The second direction addresses a more general problem that affects all existing machine-learning frameworks to some extent, in that for most users, the system is a 'black box'. The priority for software designers is to produce systems with equivalent performance to that of human experts, and the requirement to explain decisions made, particularly within an operational context, is a secondary concern. Building systems that can be trained by domain experts rather than by computer programmers might offer a solution. With intelligent system applications ranging from clinical decision-making, autonomous driving, financial services, and predictive policing comes the growing need for accountability. In this context, the exposure of the decision-making logic is not just a legal necessity but can prevent system errors and build trust amongst users. Details of a potential 'right to explanation' were debated in the most recent revision of the EU's General Data Protection Regulation (GDPR) (Goodman \& Flaxman 2016). While current legislation requires explanations only in very limited contexts, questions around operational explanation are expected to become more important in the future. In fisheries management, the development of appropriate computational frameworks that support explanations could begin by exposing the human-computer interactions that occur when the system is trained. Open-access logging of this decision process could be used to reduce inter-reader variation, improve quality assurance and perhaps play a role in training future generations of otolith readers.

\section{CONCLUSIONS}

Digital otolith imagery is easy to acquire and relatively cheap to store compared with physical specimens, which may degrade with age; its use in otolith science is already well established and will become increasingly important, particularly for projects involving long chronological time-series. Fisheries management has benefitted from CAAGE systems that exploit both fully automatic and interactive paradigms. However, the cost-benefit analysis reviewed in this paper shows that imaging systems are currently unable to deliver accuracies comparable with systems using models built on morphologic features or age-length keys based on estimates from expert readers, and using current systems, any associated cost-savings will be marginal at best. However, image-based information has been shown to improve age estimates using morphological features, and in the short term, future research should focus on refining this approach.
Acknowledgements. We thank Prof. Duncan Bell, School of Science, Technology and Health, University Campus Suffolk, UK, and David Mortimer, Newbourne Solutions Ltd. for their help creating Fig. 1. We also thank Dr. Timothy Rowe (www.digimorph.org) for permission to use the 3-D microCT data set. This review was inspired by a pilot study undertaken by Joe Scutt Phillips at Cefas and we would like to acknowledge the support of Wendy Dawson and Mark Etherton in securing funding for this work. We also thank Sally Songer for her help in recovering and interpreting otolith images. A recently established strategic alliance between Cefas and the University of East Anglia (UEA) provided a framework supporting further interdisciplinary research in the area and we thank both partners for their financial support. We are also grateful to Kelig Mahé and the anonymous referees whose comments greatly improved an earlier version of this review.

\section{LITERATURE CITED}

Abràmoff M, Magalhães P, Ram S (2004) Image processing with ImageJ. Biophoton Int 11:36-42

Álvarez A, Morales-Nin B, Palmer M, Tomás J, Sastre J (2008) A two-dimension otolith growth inverse model. J Fish Biol 72:512-522

Appelberg M, Formigo N, Geffen A, Hammer C and others (2005) A cooperative effort to exchange age reading experience and protocols between European fish institutes. Fish Res 76:167-173

Arneri E, Bergstrom N, Cardinale M, Claes E and others (2002) FAbOSA: Fish Ageing by Otolith Shape Analysis: final report to the European Commission. EC contract no. FAIR CT97 3402. www.ices.dk/community/Documents/ PGCCDBS/fabosa_rapp02_hel.pdf (accessed 26 April 2018)

*Begg G, Campana S, Fowler A, Suthers I (2005) Otolith research and application: current directions in innovation and implementation. Mar Freshw Res 56:477-483

Benzinou A, Troadec H, Binhant JL, Rodin V, de Pontual H, Tisseau J (1997) A locally deformable B-Bubble model: an application to growth ring detection on fish otoliths. In: Proc 10th Scand Conf Image Analysis, p 181-187

Bermejo S (2007) Fish age classification based on length, weight, sex and otolith morphological features. Fish Res 84:270-274

Bermejo S (2014) The benefits of using otolith weight in statistical fish age classification: a case study of Atlantic cod species. Comput Electron Agric 107:1-7

*Back BA, Boehlert GW, Yoklavich MM (2005) Using treering crossdating techniques to validate annual growth increments in long-lived fishes. Can J Fish Aquat Sci 62: 2277-2284

Brophy D (2014) Chapter eight - Analysis of growth marks in calcified structures: insights into stock structure and migration pathways. In: Cadrin SX, Kerr LA, Mariani S (eds) Stock identification methods, 2nd edn. Academic Press, San Diego, CA, p 141-170

*Burke N, Brophy D, King P (2008a) Otolith shape analysis: its application for discriminating between stocks of Irish Sea and Celtic Sea herring (Clupea harengus) in the Irish Sea. ICES J Mar Sci 65:1670-1675

* Burke N, Brophy D, King PA (2008b) Shape analysis of otolith annuli in Atlantic herring (Clupea harengus); a new method for tracking fish populations. Fish Res 91:133-143 
Cadima EL (2003) Fish stock assessment manual. FAO Fish Tech Pap No. 393. www.fao.org/3/a-x8498e.pdf (accessed 26 April 2018)

Cadrin SX, Dickey-Collas M (2015) Stock assessment methods for sustainable fisheries. ICES J Mar Sci 72:1-6

Cailliet GM, Botsford LW, Brittnacher JG, Ford G and others (1996) Development of a computer-aided age determination system: evaluation based on otoliths of bank rockfish off California. Trans Am Fish Soc 125:874-888

Campana S (1987) Image analysis for microscope based observation: an inexpensive configuration. Can Tech Rep Fish Aquat Sci No. 1569

Campana SE (1992) Measurement and interpretation of the microstructure of fish otoliths. In: Stevenson D, Campana $\mathrm{S}$ (eds) Otolith microstructure examination and analysis. Can Spec Publ Fish Aquat Sci 117:59-71

Campana S (2001) Accuracy, precision and quality control in age determination, including a review of the use and abuse of age validation methods. J Fish Biol 59: $197-242$

Campana S (2005) Otolith science entering the 21st century. Mar Freshw Res 56:485-495

Campana S, Casselman J (1993) Stock discrimination using otolith shape analysis. Can J Fish Aquat Sci 50: 1062-1083

Campana S, Fowler G (2012) Age determination without tears: statistical estimation of silver hake (Merluccius bilinearis) age composition on the basis of otolith weight and fish length. DFO Can Sci Advis Sec Res Doc 2012/079

Campana S, Neilson J (1985) Microstructure of fish otoliths. Can J Fish Aquat Sci 42:1014-1032

Campana S, Thorrold S (2001) Otoliths, increments, and elements: keys to a comprehensive understanding of fish populations. Can J Fish Aquat Sci 58:30-38

* Cao F, Fablet R (2006) Automatic morphological detection of otolith nucleus. Pattern Recognit Lett 27:658-666

Carbini S, Chessel A, Benzinou A, Fablet R (2008) A review of image-based tools for automatic fish ageing from otolith features. In: Proc Approche Systémique des Pêches, Boulogne-sur-Mer, p 1

Cardinale M, Doering-Arjes P, Kastowsky M, Mosegaard H (2004) Effects of sex, stock, and environment on the shape of known-age Atlantic cod (Gadus morhua) otoliths. Can J Fish Aquat Sci 61:158-167

* Caselles V, Morel J, Sbert C (1998) An axiomatic approach to image interpolation. IEEE Trans Image Process 7 : 376-386

Casselman J, Scott K (2000) A general procedures manual for CSAGES-Calcified Structure Age-Growth data Extraction Software (version 5.2). Spec Publ Glenora Fisheries Stn. Ontario Ministry of Natural Resources, Picton

Chauvelon P, Bach P (1993) Modelling the otolith shape as an ellipse: an attempt for back-calculation purposes. ICES J Mar Sci 50:121-128

Chessel A, Cao F, Fablet R (2006) Interpolating orientation fields: an axiomatic approach. In: Proc 9th Eur Conf Computer Vision, Part IV, ECCV'06. Springer-Verlag, Berlin, p 241-254

Chessel A, Fablet R, Kervrann C, Cao F (2008) Otolith image analysis by computer vision: extraction of growth rings and recovering shape evolution of acretionary structures. In: Proc Int Conf Bio-Insp Signal Process Syst Biosignal 2008, p 490-497

Christensen JM (1984) Burning of otoliths, a technique for age determination of soles and other fish. J Cons Int Explor Mer 29:73-81

Clausen LW, Davis CG, Hansen S (2006) Report of the Sand Eel Otolith Ageing Workshop, DIFRES Charlottenlund, Denmark 11-13 September 2006. www.ices.dk/ community/Documents/PGCCDBS/ReportSandEelAge WK0906.pdf (accessed 26 April 2018)

Courbin N, Fablet R, Mellon C, de Pontual H (2007) Are hake otolith macrostructures randomly deposited? Insights from an unsupervised statistical and qualitative approach applied to Mediterranean hake otoliths. ICES J Mar Sci 64:1191-1201

* Darnaude AM, Sturrock A, Trueman CN, Mouillot D, Campana SE, Hunter E (2014) Listening in on the past: What can otolith ${ }^{18} \mathrm{O}$ values really tell us about the environmental history of fishes? PLOS ONE 9:e114951

* de Pontual H, Groison AL, Piñeiro C, Bertignac M (2006) Evidence of underestimation of European hake growth in the Bay of Biscay, and its relationship with bias in the agreed method of age estimation. ICES J Mar Sci 63: 1674-1681

* Doering-Arjes P, Cardinale M, Mosegaard H (2008) Estimating population age structure using otolith morphometrics: a test with known-age Atlantic cod (Gadus morhua) individuals. Can J Fish Aquat Sci 65:2342-2350

Easey M, Millner R (2008) Improved methods for the preparation and staining of thin sections of fish otoliths for age determination. Sci Ser Tech Rep 143. Cefas, Lowestoft

Estep K, Nedreaas K, MacIntyre F (1995) Computer image enhancement and presentation of otoliths. In: Secor D, Dean J, Campana S (eds) Recent developments in fish otolith research. Belle W. Baruch Institute for Marine Biology and Coastal Research. University of South Carolina Press, Columbia, SC, p 303-317

Fablet R (2005) Extraction and interpretation of ring structures in images of biological hard tissues: application to fish age and growth estimation. In: Proc IEEE Int Conf Image Processing, Vol 2, p 830-833

Fablet R (2006a) Semi-local extraction of ring structures in images of biological hard tissues: application to the Bayesian interpretation of fish otoliths for age and growth estimation. Can J Fish Aquat Sci 63:1414-1428

Fablet R (2006b) Statistical learning applied to computerassisted fish age and growth estimation from otolith images. Fish Res 81:219-228

Fablet R, Le Josse N (2005) Automatic fish age estimation from otolith images using statistical learning. Fish Res 72:279-290

Fablet R, Ogor A (2005) TNPC: digital processing for calcified structures. www.ifremer.fr/lasaa/TNPC/manuel_ tnpc4.pdf

Fablet R, Benzinou A, Doncarli C (2003) Robust time-frequency model estimation in otolith images for fish age and growth analysis. In: Proc IEEE Int Conf Image Processing, Vol 3, p 593-596

F Fablet R, Le Josse N, Benzinou A (2004) Automatic fish age estimation from otolith images using statistical learning. In: Proc 17th Int Conf Pattern Recognition, Vol 4, p 503-506

Fablet R, Pujolle S, Chessel A, Benzinou A, Cao F (2008) 2D image-based reconstruction of shape deformation of biological structures using a level-set representation. Comput Vis Image Underst 111:295-306

Fablet R, Chessel A, Carbini S, Benzinou A, de Pontual H (2009) Reconstructing individual shape histories of fish 
otoliths: a new image-based tool for otolith growth analysis and modelling. Fish Res 96:148-159

Fablet $\mathrm{R}$, Pecquerie L, de Pontual H, Høie H, Millner R, Mosegaard H, Kooijman S (2011) Shedding light on fish otolith biomineralization using a bioenergetic approach. PLOS ONE 6:e27055

Fawel J (1974) The use of image analysis in the ageing of fish. In: Bagenal T (ed) The ageing of fish. Unwin Brothers, London, p 103-107

Fey D P, Linkowski TB (2006) Predicting juvenile Baltic cod (Gadus morhua) age from body and otolith size measurements. ICES J Mar Sci 63:1045-1052

Formella A, Vázquez JM, Carrión P, Cernadas E, Vázquez A, Pérez-Gándaras G (2007) Age reading of cod otoliths based on image morphing, filtering and Fourier analysis. In: 7th IASTED Int Conf Visualization, Imaging and Image Processing, VIIP '07. ACTA Press, Anaheim, CA, p 207-212. http://dl.acm.org/citation.cfm?id=1659167. 1659207 (accessed 26 April 2018)

Francis RC, Campana SE (2004) Inferring age from otolith measurements: a review and a new approach. Can J Fish Aquat Sci 61:1269-1284

Frei R (1982) Measurements of fish scales and back-calculation of body lengths using a digitizing pad and microcomputer. Fisheries 7:5-8

Friedland KD, Reddin DG (1994) Use of otolith morphology in stock discriminations of Atlantic salmon (Salmo salar). Can J Fish Aquat Sci 51:91-98

Geffen A (2002) Length of herring larvae in relation to age and time of hatching. J Fish Biol 60:479-485

Geffen AJ (2012) Otolith oxygen and carbon stable isotopes in wild and laboratory-reared plaice (Pleuronectes platessa). Environ Biol Fishes 95:419-430

Gonzalez RC, Woods RE (2008) Digital image processing, 3rd edn. Pearson Education, Upper Saddle River, NJ

Goodman B, Flaxman S (2016) EU regulations on algorithmic decision-making and a 'right to explanation'. In: ICML workshop on human interpretability in machine learning. WHI 2016, New York, NY. https://pdfs. semanticscholar.org/f051/55c4d7d77f32855b80a86bb98 7818838d50d.pdf (accessed 27 April 2018)

* Grønkjaer P (2016) Otoliths as individual indicators: a reappraisal of the link between fish physiology and otolith characteristics. Mar Freshw Res 67:881-888

* Guillaud A, Benzinou A, Troadec H, Rodin V, Bihan JL (2002a) Autonomous agents for edge detection and continuity perception on otolith images. Image Vis Comput 20:955-968

Guillaud A, Troadec H, Benzinou A, Le Bihan J, Rodin V (2002b) A multiagent system for edge detection and continuity perception on fish otolith images. EURASIP J Adv Signal Process 2002:756043

Hamrin SF, Arneri E, Doering-Arjes P, Mosegaard H and others (1999) A new method for three-dimensional otolith analysis. J Fish Biol 54:223-225

Healey B, Mahe K, Cossitt G, Dufour JL and others (2011) Age determination of Atlantic cod Gadus morhua: results from an otolith exchange between Canada and France. Tech Rep Can Sci Advis Sec Res Doc 2011/015. http:// archimer.ifremer.fr/doc/00035/14627/ (accessed 26 April 2018)

Hüssy K, Mosegaard H (2004) Atlantic cod (Gadus morhua) growth and otolith accretion characteristics modelled in a bioenergetics context. Can J Fish Aquat Sci 61: 1021-1030
Hüssy K, Radtke K, Plikshs M, Oeberst R and others (2016a) Challenging ICES age estimation protocols: lessons learned from the eastern Baltic cod stock. ICES J Mar Sci 73:2138-2149

* Hüssy K, Mosegaard H, Albertsen CM, Nielsen EE, Hemmer-Hansen J, Eero M (2016b) Evaluation of otolith shape as a tool for stock discrimination in marine fishes using Baltic Sea cod as a case study. Fish Res 174: 210-218

Jolivet A, Bardeau JF, Fablet R, Paulet YM, de Pontual H (2008) Understanding otolith biomineralization processes: new insights into microscale spatial distribution of organic and mineral fractions from Raman microspectrometry. Anal Bioanal Chem 392:551-560

Jolivet A, Bardeau JF, Fablet R, Paulet YM, de Pontual H (2013) How do the organic and mineral fractions drive the opacity of fish otoliths? Insights using Raman microspectrometry. Can J Fish Aquat Sci 70:711-719

Kalish JM, Beamish RJ, Brothers EB, Casselman JM and others (1995) Glossary for otolith studies. In: Secor DH, Dean JM, Campana SE (eds) Recent developments in fish otolith research. University of South Carolina Press, Columbia, SC, p 723-729. http://horizon.documentation. ird.fr/exl-doc/pleins_textes/pleins_textes_6/b_fdi_35-36/ 42209.pdf (accessed 26 April 2018)

King AE (1993) Determination of bank rockfish age and growth: a comparison of traditional and computer-aided techniques. MSc thesis, San Jose State University, San Jose, CA. http://scholarworks.sjsu.edu/etd_theses/687/ (accessed Sep 25, 2013)

KLombarte A, Morales-Nin B (1995) Morphology and ultrastructure of saccular otoliths from five species of the genus Coelorinchus (Gadiformes: Macrouridae) from the Southeast Atlantic. J Morphol 225:179-192

* Lombarte A, Chic Ò, Parisi-Baradad V, Olivella R, Piera J, García-Ladona E (2006) A web-based environment for shape analysis of fish otoliths. The AFORO database. Sci Mar 70:147-152

Macy WI (1995) The application of digital image processing to aging of long-finned squid, Loligo pealei, using the statolith. In: Secor D, Dean J, Campana S (eds) Recent developments in fish otolith research. University of South Carolina Press, Columbia, SC, p 283-302

* Mahé K (2009) Project no. 044132 Automated FISh Ageing (AFISA): final activity report. www.ices.dk/exploreus/projects/EU-RFP/EU\%20Repository/AFISA/FP6 \% 20 AFISA \%20Final\%20Activity\%20Report.pdf (accessed 26 April 2018)

* Mahé K, Fave S, Couteau J (2011) TNPC User guide. http://archimer.ifremer.fr/doc/00032/14288/ (accessed 26 April 2018)

* Mahé K, Aumond Y, Rabhi K, Elleboode R and others (2017) Relationship between somatic growth and otolith growth: a case study of the ornate jobfish Pristipomoides argyrogrammicus from the coast of Réunion (SW Indian Ocean), Afr J Mar Sci 39:145-151

Mapp JJI, Fisher MH, Atwood RC, Bell GD, Greco MK, Songer S, Hunter E (2016) Three-dimensional rendering of otolith growth using phase contrast synchrotron tomography. J Fish Biol 88:2075-2080

Matic-Skoko S, Ferri J, Skeljo F, Bartulovic V, Glavic K, Glamuzina B (2011) Age, growth and validation of otolith morphometrics as predictors of age in the forkbeard, Phycis phycis (Gadidae). Fish Res 112:52-58

McGowen M, Prince E, Lee D (1987) An inexpensive micro- 
computer-based system for making rapid and precise counts and measurements of zonations in video displayed skeletal structures of fish. In: Summerfelt R, Hall G (eds) Age and growth of fish. Iowa State University Press, Ames, IA, p 385-395

Mendoza RR (2006) Otoliths and their applications in fishery science. Ribarstvo 64:89-102

Messieh SN (1972) Use of otoliths in identifying herring stocks in the southern Gulf of St. Lawrence and adjacent waters. J Fish Res Board Can 29:1113-1118

Messieh S, McDougall C (1985) A computer based method for separating herring spawning groups using digitized otolith morphometrics. Can Atl Fish Sci Advis Comm (CAFSAC) Res Doc 85/106

Methot RD Jr (1981) Spatial covariation of daily growth rates of larval northern anchovy, (Engraulis mordax), and northern lampfish, (Stenobrachius leucopsarus). Rapp PV Reun Cons Int Explor Mer 178:424-431

Mille T, Mahé K, Cachera M, Villanueva M, de Pontual H, Ernande B (2016) Diet is correlated with otolith shape in marine fish. Mar Ecol Prog Ser 555:167-184

Miller J, Simenstead C (1994) Otolith microstructure preparation, analysis and interpretation: procedures for a potential habitat assessment methodology. Fish Res Inst Tech Rep FRI-UW-9406. School of Fisheries, University of Washington, Seattle, WA

Millner R, Pilling G, McCully S, Høie H (2011) Changes in the timing of otolith zone formation in North Sea cod from otolith records: an early indicator of climateinduced temperature stress? Mar Biol 158:21-30

Moksness E (2000) FAIR-CT 96.1304 European Fish Aging Network (EFAN): final report. ftp://ftp.imr.no/tobi/Efan/ (accessed 26 April 2018)

Morales-Nin B, Geffen AJ (2015) The use of calcified tissues as tools to support management: the view from the 5th International Otolith Symposium. ICES J Mar Sci 72: 2073-2078

Morales-Nin B, Panfili J (2002) Sclerochronological studies: age estimation. In: Panfili J, de Pontual $\mathrm{H}$, Troadec $\mathrm{H}$, Wright P (eds) Manual of fish sclerochronology. IFREMER-IRD, Brest, p 91-98

Morales-Nin B, Lombarte A, Japòn B (1998) Approaches to otolith age determination: image signal treatment and age attribution. Sci Mar 62:247-256

*Morison A, Robertson S, Smith D (1998) An integrated system for production fish aging: image analysis and quality assurance. N Am J Fish Manage 18:587-598

Morison AK, Burnett J, McCurdy WJ, Moksness E (2005) Quality issues in the use of otoliths for fish age estimation. Mar Freshw Res 56:773-782

*Morrongiello JR, Thresher RE, Smith DC (2012) Aquatic biochronologies and climate change. Nat Clim Change 2:849-857

Neat F, Wright P, Fryer R (2008) Temperature effects on otolith pattern formation in Atlantic cod Gadus morhua. J Fish Biol 73:2527-2541

Palmer M, Àlvarez A, Tomàs J, Morales-Nin B (2005) A new method for robust feature extraction of otolith growth marks using fingerprint recognition methods. Mar Freshw Res 56:791-794

Panfili J, Ximenes MC, Do Chi T (1990) Age determination of eels in the French Mediterranean lagoons using classical methods and an image analysis system. Int Rev Gesamten Hydrobiol Hydrograph 75:745-754

Panfili J, de Pontual H, Troadec H, Wright P (eds) (2002)
Manual of fish sclerochronology. Ifremer-IRD, Brest

* Parisi-Baradad V, Manjabacas A, Lombarte A, Olivella R, Chic Ò, Piera J, García-Ladona E (2010) Automated taxon identification of teleost fishes using an otolith online database AFORO. Fish Res 105:13-20

Popper A, Hoxter B (1981) The fine structure of the sacculus and lagena of a teleost fish. Hear Res 5:245-263

Popper A, Lu Z (2000) Structure-function relationships in fish otolith organs. Fish Res 5:245-263

*Popper AN, Ramcharitar J, Campana SE (2005) Why otoliths? Insights from inner ear physiology and fisheries biology. Mar Freshw Res 56:497-504

Ricker W (1975) Computation and interpretation of biological statistics of fish populations. Bull Fish Res Board Can 191:382

Robertson SG, Morison AK (1999) A trial of artificial neural networks for automatically estimating the age of fish. Mar Freshw Res 50:73-82

Robertson S, Morison A (2001) Development of an artificial neural network for automated age estimation. Tech Rep 98/105. Marine and Freshwater Resources Institute

* Rodin V, Troadec H, de Pontual H, Benzinou A, Tisseau J, Le Bihan J (1996) Growth ring detection on fish otoliths by a graph construction. In: Proc IEEE Int Conf Image Processing, Vol 2, p 685-688

Rypel A (2008) An inexpensive image analysis system for fish otoliths. N Am J Fish Manage 28:193-197

Schmidt W (1969) The otoliths as a means for differentiation between species of fish of very similar appearance. In: Proc Symp Oceanogr Fish Resour Trop Atlantic, p 393-396

* Schulz-Mirbach T, Ladich F, Plath M, Hess M (2015) The role of otolith size in hearing - insights from cichlid fishes. Front Mar Sci 34

Sethian J (1996) Level set methods. Cambridge University Press, Cambridge

Small G, Hirschhorn G (1987) Computer-assisted age and growth pattern recognition of fish scales using a digitizing tablet. In: Summerfelt G (ed) Age and growth of fish. Iowa State University Press, Ames, IA, p 397-410

Smith J (2014) Age validation of lemon sole (Microstomus kitt), using marginal increment analysis. Fish Res 157: 41-46

Smith SJ, Campana SE (2010) Integrated stock mixture analysis for continous and categorical data, with application to genetic-otolith combinations. Can J Fish Aquat Sci 67:1533-1548

Smolinski S, Mirny Z (2017) Otolith biochronology as an indicator of marine fish responses to hydroclimatic conditions and ecosystem regime shifts. Ecol Indic 79: 286-294

Sonka M, Hlavac V, Boyle R (2008) Image processing, analysis and machine vision, 3rd edn. Cengage Learning, Stamford, CT

Sória Pérez JA (2012) On the automatic detection of otolith features for fish species identification and their age estimation. PhD thesis, Universitat Politècnica de Catalunya, Barcelona

Sturrock AM, Trueman CN, Darnaude AM, Hunter E (2012) Can otolith elemental chemistry retrospectively track migrations in fully marine fishes? J Fish Biol 81:766-795

Sturrock AM, Hunter E, Milton JA, EIMF, Johnson RC, Waring CP, Trueman CN (2015) Quantifying physiological influences on otolith microchemistry. Methods Ecol Evol 6:806-816 
Takashima Y, Takada T, Matsuishi T, Kanno Y (2000) Validation of auto-counting method by NIH image using otoliths of white-spotted char Salvelinus leucomaenis. Fish Sci 66:515-520

Troadec H (1991) Frequency demodulation on otolith numerical images for the automation of fish age estimation. Aquat Living Resour 4:207-219

Troadec H, Benzinou A (2002) Computer-assisted age estimation. In: Panfili J, de Pontual $\mathrm{H}$, Troadec $\mathrm{H}$, Wright $\mathrm{P}$ (eds) Manual of fish sclerochronology. Ifremer-IRD, Brest, p 199-241

Troadec H, Benzinou A, Rodin V, Bihan JL (2000) Use of deformable templates for otolith 2D growth ring detection by digital image processing. Fish Res 46:155-163

Vischer N, Nastase S (2015) ObjectJ otolith and tree ring counter. https://sils.fnwi.uva.nl/bcb/objectj/examples/ TreeRings/TreeRings-9.htm

Welch TJ, van den Avyle MJ, Betsill RK, Driebe EM (1993) Precision and relative accuracy of striped bass age estimates from otoliths, scales, and anal fin rays and spines. N Am J Fish Manage 13:616-620

Welleman H, Storbeck F (1995) Automatic ageing of plaice (Pleuronectes platessa L.) otoliths by means of image analysis. In: Secor D, Dean J, Campana S (eds) Recent developments in fish otolith research. University of South

Editorial responsibility: Stylianos Somarakis, Heraklion, Greece
Carolina Press, Columbia, SC, p 271-282

* Whitman G, Johnson RC (2016) Imaging of otoliths for analysis of fish age and growth: a guide for measuring daily increments in adult and juvenile otoliths using

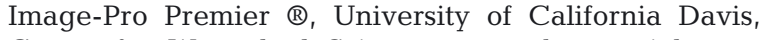
Center for Watershed Sciences. www.barnett-johnson. com/uploads/1/9/9/0/1990941/increment_measurement_ sop_v2.0_final.pdf (accessed 27 April 2018)

Williams T, Bedford B (1974) The use of otoliths for age determination. In: Bagenal $\mathrm{T}$ (ed) The ageing of fish. Unwin Brothers, Surrey, p 114-123

Williams AJ, Newman SJ, Wakefield CB, Bunel M, Halafihi T, Kaltavara J, Nicol SJ (2015) Evaluating the performance of otolith morphometrics in deriving age compositions and mortality rates for assessment of data-poor tropical fisheries. ICES J Mar Sci 72:2098-2109

* Yaragina NA, Nedreaas KH, Koloskova VP, Mjanger H, Senneset H, Zuykova NV, Gotnes P (2009) Fifteen years of annual Norwegian-Russian cod comparative age readings. Mar Biol Res 5:54-65

* Zhu X, Wastle RJ, Howland KL, Leonard DJ, Mann S, Carmichael TJ, Tallman RF (2015) A comparison of three anatomical structures for estimating age in a slow-growing subarctic population of lake whitefish. N Am J Fish Manage 35:262-270

Submitted: June 28, 2017; Accepted: February 14, 2018 Proofs received from author(s): April 27, 2018 